\title{
QUÍMICA NA COZINHA: IDENTIFICANDO O SÓDIO EM ALGUNS ALIMENTOS.
}

\section{CHEMISTRY IN THE KITCHEN: IDENTIFYING THE SODIUM IN SOME FOODS.}

\author{
Maioneide Madalena de Jesus ${ }^{1}$; Ronaldo José dos Santos²; Wanderléia Mércia Mello da
} Silva ${ }^{3}$; Francisco de Assis Pereira Neto ${ }^{4}$.

\section{INTRODUÇÃO}

O presente trabalho através de uma pesquisa de natureza qualitativa exploratória do tipo experimental visa analisar e identificar o sódio em alguns alimentos, através da sua coloração emitida na chama do bico de Bunsen, sendo possível analisar cátions presentes em substâncias de fácil acesso no dia a dia, onde na maioria das vezes a população ingere determinados elementos sem conhecer seus constituintes e, com essa análise pode se perceber e saber um componente químico comum nesses alimentos.

O teste experimental foi realizado no laboratório de Química do Instituto Federal de Educação, Ciência e Tecnologia do Piauí - Campus Picos. Neste experimento foi utilizado o sal de cozinha, caldo de carne e fermento biológico em pó ou bicarbonato de sódio, juntamente com o Bico de Bunsen. Com intuito de verificar através da cor da chama emitida no Bico de Bunsen qual elemento químico estava presente em cada substância, pois de acordo com Baccan (1988) quando certa quantidade de elétrons de algum elemento é excitado pela temperatura produzida pelo Bico de Bunsen, estes quando retornam ao estado fundamental de cor e intensidade emitem luz através da chama, tornando assim detectável e identificável, quando observado visualmente na chama.

Portanto com a análise feita foi possível identificar que esse cátion está presente nos três produtos citados, observando uma coloração amarelo intenso nas três substâncias, típico do cátion analisado. Para fundamentação deste trabalho, usou se de algumas obras científicas, artigos acadêmicos, conhecimentos adquiridos em sala de aula e pesquisas bibliográficas. $\mathrm{O}$ que contribuiu significativamente para um maior aprendizado e conhecimento químico, além de nos levar a pensar e querer conhecer mais acerca dos constituintes químicos daquilo que é ingerido, podendo assim perceber que a química está presente até no que consumimos.

\section{FUNDAMENTAÇÃO TEÓRICA}

O conhecimento da Tabela periódica e seus elementos químicos são conhecidos por várias pessoas, mas muitas vezes essas desconhecem que alguns destes elementos estão ou não presentes em alguns alimentos segundo Guerra et al (2013). Podendo ser prejudicial à saúde quando ingeridos em excesso. Por isso é necessário o conhecimento sobre a existência 
destes elementos nos alimentos.

Uma maneira de identificar que elemento está presente em determinado alimento quando for consumir é por via seca, através do teste da chama, criado por Robert Bunsen. Onde o elemento a ser analisado é colocado em contato com a chama, para que assim seja produzida uma coloração referente á substância ali presente, que de acordo com Gracetto, Hioka e Filho (2006) essas cores geradas são originadas através da estrutura eletrônica dos átomos, que indica a presença de metais na chama. Que quando excitados, os elétrons desses átomos são promovidos a estados excitados e, quando retorna ao seu estado eletrônico inicial emitem energia na forma de luz.

Alguns elementos químicos quando expostos a esse tipo de teste, emitem cores respectivas para seus íons/elétrons, o elemento Sódio $\left(\mathrm{Na}^{+}\right)$, por exemplo, apresenta cor amarelo dourado, como afirma Vogel (1989), podendo se observar uma coloração emitida na chama, amarelo alaranjada, bem intenso. Tornando assim fácil a sua identificação.

\section{METODOLOGIA}

Para o desenvolvimento deste trabalho de natureza de pesquisa exploratória do tipo experimental, teve como campo para realização do experimento o Laboratório de Química do Instituto Federal de Educação, Ciência e Tecnologia do Piauí - Campus Picos, onde utilizouse do teste da chama para análises das substâncias. Foi necessário para a idealização desse teste os seguintes materiais: bastão de vidro, algodão comercial, ácido clorídrico concentrado, sal de cozinha, fermento biológico em pó (bicarbonato de sódio), fósforo, béquer pequeno, tablete de caldo de carne, vidro de relógio, bico de Bunsen e pipeta de vidro.

O experimento se deu da seguinte forma; pegou-se pequenas porções de sal de cozinha, fermento químico em pó e tabletes de caldo de carne triturado e distribuiu- se em vidros de relógio, separadamente. Com auxílio da pipeta colocou- se uma pequena quantidade de ácido clorídrico no béquer, e com o bastão de vidro enrolado com algodão, como se fosse um "cotonete", mergulhou se no ácido clorídrico e em seguida passando no sal de cozinha, colocando em contato com a chama do bico de Bunsen, repetiu se o mesmo procedimento para o fermento químico em pó e o caldo de carne triturado, observando assim, a presença de substancia química a partir da coloração emitida na chama.

\section{RESULTADOS E DISCUSSÕES}

Ao analisarmos o sal de cozinha, o fermento biológico em pó e o caldo de carne, podemos constatar de acordo com a tabela, a coloração emitida: 
Tabela 1: Identificação do Sódio

\begin{tabular}{ll}
\hline REAGENTES & COLORAÇÃO \\
\hline Caldo de carne & Amarelo intenso \\
Fermento biológico em pó & Amarelo intenso \\
Sal de cozinha & Amarelo intenso \\
\hline
\end{tabular}

Autoria própria.

Segundo Atkins e Jones (2012), os nossos olhos conseguem detectar a radiação eletromagnética de comprimento de onda entre $700 \mathrm{~nm}$ (luz vermelha) e $400 \mathrm{~nm}$ (luz violeta), que corresponde à região da radiação chamada luz visível. Como o Sódio possui um comprimento de onda de 589,0 e 589,6 nm, ou seja, com esse comprimento de onda, é possível a identificação do mesmo. Este teste é altamente sensível e permite detectar concentrações de sódio tão baixas, menor que $5 \times 10^{-5} \mathrm{~mol} / \mathrm{L}^{-1}$. A emissão de luz desse cátion produz uma coloração amarelo intenso persistente, podendo ser facilmente detectado com simples testes analíticos. Um deles é o teste da chama que se baseia no fato de que quando certa quantidade de energia é formada a um determinado elemento químico, alguns elétrons da última camada de valência absorvem esta energia passando para um nível de energia mais elevado, produzindo o que chamamos de um estado excitado.

Quando um desses elétrons excitados retorna ao estado fundamental, emite uma quantidade de energia radiante, igual àquela absorvida, cujo comprimento de onda é característico do elemento e da mudança do nível eletrônico de energia (BACCAN, 1997). Assim, a luz de um comprimento de onda particular ou cor, é utilizada para identificar o referido elemento. A temperatura da chama do Bico de Bunsen é suficiente para excitar uma quantidade de elétrons de certos elementos que emitem luz ao retornarem ao estado fundamental de cor e intensidade, que podem ser detectadas com considerável certeza e sensibilidade através da observação visual da chama. Tal procedimento foi o utilizado para identificação do sódio.

Como podemos perceber as colorações emitidas são respectivamente, a cor correspondente a substância em análise.

\section{CONCLUSÕES}

Podemos concluir que é possível identificar através de testes por via seca, ou teste da chama, a presença de sódio em produtos alimentícios, com base na coloração emitida na chama do Bico de Bunsen, de acordo com a frequência de onda, característica de cada elemento. Sendo esse produto importante para o organismo quando usado moderadamente, ficando assim explícito que é fácil detectar a presença e a importância de substâncias químicas na alimentação. 


\section{REFERÊNCIAS}

ATKINS, P. W e JONES, L. Princípios de química:questionando a vida moderna e o meio ambiente; Tradução Ricardo Bicca de Alencastro, $3^{\mathrm{a}}$ ed. Porto Alegre: Bookman, 2006.

BACCAN, N. [et al].Introdução à semimicroanálise qualitativa. $7^{a}$ ed. Campinas, SP: Editora da Unicamp, 1997.

BACCAN, N., GODINHO. E. S. ALEIXO, O. M. STEIN. E. Introdução à semimicroanalise qualitativa. Editora Unicamp Campinas - SP. 1988.

GRACETTO, A. C; HIOKA, N; FILHO, O. S. Combustão, Chamas e Teste de Chama para Cátions: Proposta de Experimento. Química Nova na Escola. Campinas - São Paulo. 2006. Disponível em: http://qnesc.sbq.org.br/online/qnesc23/a11.pdf. Acesso em: 09/10/2018.

GUERRA, A. C. O. [et al]. Química no cotidiano: a química dos alimentos e a tabela periódica. IX Congreso Internacional sobre Investigación en didáctica de las ciências. COMUNICACIÓN: $2013 . \quad$ Girona, Disponível em: https://www.raco.cat/index.php/Ensenanza/article/viewFile/307947/397915. Acesso em: 09/10/18.

VOGEL, A.I. Textbook of macro and semimicro qualititative inorganic analysis, 5. ed, New York: Longman Group Limited, 1979. 